\title{
HEIDEGGER Y LA CUESTIÓN DEL CUERPO EN SER Y TIEMPO: BUSCANDO EL LUGAR DEL CUERPO EN LA ANALÍTICA EXISTENCIAL DEL DASEIN
}

\author{
HEIDEGGER AND THE QUESTION OF THE BODY IN BEING AND TIME: \\ SEARCHING THE PLACE OF THE BODY IN THE EXISTENTIAL \\ ANALYTIC OF DASEIN
}

\section{Rodrigo Lagos Berríos*}

Universidad de Santiago de Chile Santiago - Chile

Recibido diciembre de 2019/Received December, 2019

Aceptado mayo de 2020/Accepted May, 2020

\begin{abstract}
RESUMEN
Desde el campo de la fenomenología francesa y los estudios feministas y de género se ha criticado la ausencia del cuerpo en la ontología fundamental de Ser y tiempo desarrollada por Heidegger. En este sentido, la presente contribución no se detiene a analizar estas críticas sino que emprende la tarea de rastrear aquellos lugares y pasajes contenidos en Ser y tiempo que podrían iluminar una concepción heideggeriana del cuerpo. Además, en estos pasajes se señalan las posibles relaciones que se pueden trazar con los Seminarios de Zollikon en los que Heidegger pronuncia su propio planteamiento respecto del cuerpo, para así analizar sus posibles alcances y limitaciones.
\end{abstract}

Palabras Clave: Cuerpo, Dasein, Ontología, Espacio, Corporalidad.

\section{ABSTRACT}

From the field of French phenomenology and feminist and gender studies, the absence of the body in the fundamental ontology in Being and Time developed by Heidegger has been criticized. On this matter, the present contribution does not stop to analyze these critiques but rather undertakes the task of tracking those places and passages contained in Being and Time that could illuminate a Heideggerian conception of the body. Furthermore, these passages point out the possible relationships that can be traced with the Zollikon Seminars, in which Heidegger pronounces his own approach about the body, in order to analyze its possible scopes and limitations.

Key Words: Body, Dasein, Ontology, Space, Corporality.

\section{INTRODUCCIÓN}

Las relaciones entre cuerpo, sujeto y mundo se han constituido en un foco principal de investigación para la filosofía y, en especial, en la época contemporánea ${ }^{1}$. Muestra de esto se refleja en los estudios realizados desde el campo de la fenomenología francesa en los que el cuerpo deja de ser un objeto y una estructura pasiva, para ser concebido como dotado de intencionalidad y subjetividad. Sin embargo, el tema del cuerpo no siempre ha ocupado un lugar central en la filosofía, ya que como bien afirma la filósofa norteamericana Judith Butler (2002): "los formados en filosofía, siempre a cierta distancia de las cuestiones corpóreas, tratan de demarcar los terrenos corporales de esa manera descarnada: inevitablemente, pasan por alto el cuerpo o, lo que es peor, escriben contra él" (p. 5). En la filosofía de Heidegger, por ejemplo, el asunto del cuerpo no 
parece ser el punto de partida para iniciar la reflexión. En el campo de la fenomenología francesa y en los estudios feministas y de género se ha insistido en criticar la ausencia de una tematización explícita por parte de Heidegger acerca de la temática del cuerpo en todo Ser y tiempo.

En las últimas décadas los Studia Heideggeriana han prestado mayor atención a los asuntos relacionados con la temática del cuerpo y afectividad en el pensamiento de Heidegger editando algunos volúmenes consagrados a estos temas. En los debates actuales encontramos que existe una amplia discusión respecto del estatus del cuerpo en la filosofía heideggeriana que ha dado lugar a posturas contrarias entre los expertos ${ }^{2}$. Desde entonces han aparecido diversas investigaciones centradas en delimitar la interpretación heideggeriana de la corporalidad entre las que destacan: Ciocan (2008), Aho (2010), Escudero (2011), Rodríguez Suárez (2012), Johnson (2014b). Estas investigaciones se agrupan principalmente alrededor de los denominados Seminarios de Zollikon, cuya publicación fue por primera vez en alemán en 1987. Los Seminarios de Zollikon corresponden a un conjunto de protocolos $\mathrm{y}$ cartas de las diversas sesiones en las que se reunieron Heidegger y el psiquiatra suizo Medard Boss en la ciudad de Zollikon (Suiza), de ahí el nombre de estos seminarios ${ }^{3}$. A partir de la publicación de estos seminarios el estudio de la corporalidad en el pensamiento de Heidegger recibió un impulso decisivo, porque en ellos se puede ver a Heidegger abordando otros temas que escapan del proyecto de su ontología fundamental en Ser y tiempo. Entre estas temáticas se destacan principalmente el análisis del fenómeno del cuerpo (Leibphänomen), el estrés, las enfermedades psicosomáticas, la relación entre filosofía y ciencia, entre otras.

En Ser y tiempo, como es sabido, Heidegger dedica pocas líneas al tema de la corporalidad, lo que podría llevarnos a interpretar que el asunto del cuerpo no tendría cabida en una consideración de los caracteres fundamentales del Dasein. Pero, si esto fuera el caso, los planteamientos que Heidegger llevará a cabo años más tarde en los Seminarios de Zollikon vendrían a subsanar este silencio de Heidegger respecto del cuerpo. En una de las tantas sesiones en las que se reunió Heidegger con el psiquiatra Medard Boss leemos a continuación: "No hay propiamente una fenomenología del cuerpo porque el cuerpo (Leib) no es ningún cuerpo (Körper). Con tal tema uno ya erró el asunto (Sache)" (Heidegger,
2013, p. 272). De la cita anterior es posible desprender dos negaciones que iluminan el asunto del cuerpo. Por un lado, nos encontramos con una negación de Heidegger a desplegar una fenomenología del cuerpo, lo que podría significar que queda vetada la posibilidad de incluir el problema de la corporalidad en la analítica existencial del Dasein. Por otro lado, hay una negación de Heidegger a desarrollar un análisis fenomenológico del cuerpo que estaría relacionado con la forma en que ha sido concebido el cuerpo solo en tanto Körper, esto es, como cuerpo presente. Entonces, es preciso preguntarse si estas dos negaciones de Heidegger no obedecen a una cuestión más fundamental, a saber, la forma en que debería ser mostrado el cuerpo en vistas de la constitución fundamental del ser humano como Dasein. En primera instancia, esto nos podría indicar que la omisión de Heidegger acerca del tema del cuerpo en Ser y tiempo estaría vinculado con su propósito de dilucidar primero el modo en que el ser humano existe como Dasein, antes de iniciar cualquier consideración positiva del cuerpo. De modo que volver nuevamente a Ser y tiempo en vistas de la pregunta por el cuerpo, nos podría ayudar a identificar aquellos antecedentes que Heidegger dejó establecidos y que le permitirán luego desarrollar su propio planteamiento del cuerpo en los Seminarios de Zollikon. De igual forma, es importante comprender por qué Heidegger decide finalmente emprender una reflexión de un tema, como lo es el cuerpo, que en su opinión ya estaba cerrado.

En vistas de lo anterior el presente artículo persigue los siguientes objetivos: 1) En primer lugar se exhiben algunas de las críticas que se le han formulado a la ausencia del cuerpo en Ser y tiempo, así como sus posibles justificaciones o explicaciones, para así 2) mostrar la ausencia del cuerpo en Ser y tiempo, para luego 3) analizar la espacialidad del Dasein y su respectiva relación con la espacialidad del cuerpo. Finalmente 4) se reflexiona acerca de la ambigüedad de lo corporal en Heidegger y se entregan algunas conclusiones que se desprenden de la interpretación ontológica del cuerpo en Heidegger.

\section{EL REPROCHE DE SARTRE A HEIDEGGER}

El denominado "olvido del cuerpo" (Leibvergessenheit) en Ser y tiempo es mucho más pertinente si lo evaluamos a la luz de los debates de 
la fenomenología contemporánea, donde la temática del cuerpo es central en la investigación ${ }^{4}$. Mientras que en Ser y tiempo hayamos solo una referencia al tema de la corporalidad en el marco de la espacialidad del Dasein cuando este manipula los entes en el mundo inmediato (Escudero, 2011). De ahí que sea habitual que se acuse a Heidegger y a su análisis de la existencia humana de olvidarse por completo del cuerpo. Esta crítica es especialmente frecuente en el campo de la fenomenología francesa, ya que los análisis fenomenológicos realizados por Jean-Paul Sartre y Maurice Merleau-Ponty le otorgaron al cuerpo un rol protagónico como primer anclaje de la existencia en el mundo (Gallo, 2006). Sin duda, Sartre será uno de los primeros filósofos que reprochará a Heidegger una carencia en el tratamiento de la corporalidad en todo $\mathrm{Ser}$ y tiempo. Para Sartre en Ser y tiempo Heidegger dedica solo seis líneas para hablar del problema de la corporalidad, motivo por el cual la analítica existencial le parece insuficiente. En El Ser y la nada Sarte señalará lo siguiente:

Las filosofías existenciales no han creído que debieran preocuparse de la sexualidad. Heidegger, en particular, no alude para nada a ella en su analítica existencial, de suerte que su Dasein nos aparece como asexuado (...) sin duda, puede decirse que el problema de la diferenciación sexual nada tiene que ver con el de la Existencia (Existenz). (Sartre, 1993, p. 407)

De lo anterior se desprende que para Sartre el Dasein de Heidegger aparece como asexuado en la analítica existencial, ya que carece principalmente de una diferenciación sexual, es decir, de una determinación corporal o física. No obstante, esta "asexualidad" que denuncia Sartre es precisamente uno de los principales rasgos ontológicos del Dasein de Heidegger. Como explica Heidegger en relación con el Dasein, "la interpretación del ente se lleva a cabo antes de toda concreción fáctica" (Heidegger, 2009, p. 160). Para Heidegger la interpretación del ser humano como Dasein es previa a cualquier condición de género, raza, cultura, etnia, etc. El significado del término Dasein para Heidegger solo puede entenderse si se le considera como anterior a toda determinación o concreción fáctica, ya sea como hombre o como mujer. Esto queda en evidencia en las lecciones del semestre de invierno 1928/29 cuando Heidegger sostiene lo siguiente:
En su esencia, la entidad que somos es algo neutral. Lo llamamos Dasein. Sin embargo, pertenece a la esencia de este ente neutral el hecho de que, mientras existe fácticamente (...) ha roto necesariamente su neutralidad, es decir, no es ni masculino ni femenino; simplemente es una criatura sexual (Geschlechtwesen). (Heidegger, 2001, p. 152)

A partir de las palabras de Heidegger es posible deducir que para él lo originario es la neutralidad (Neutralität) sexual, ya que solo por esta es posible la diferenciación sexual. Para Heidegger el sexo sería entonces solo un momento del "estar arrojado" (Geworfenheit), ya que aquí tendrían cabida las distintas posibilidades fácticas del Serunos-con-otros (Miteinandersein). Para Derrida, por ejemplo, la falta de diferenciación de los sexos no es originaria como un silencio de Heidegger, sino que esta asexualidad (Geschlechtslosigkeit) del Dasein "no significa que carezca de sexualidad, esto es, de pulsión, de deseo, incluso de libido, sino que se refiere a la ausencia de marca de pertenencia a uno de los dos sexos" (Derrida, 1992, p. 111). Desde el análisis de Derrida la falta de pronunciamiento de Heidegger de la diferenciación sexual no se tiene que entender como pura negatividad, esto es, como una especie de negación de la sexualidad del Dasein. Por el contrario, el Dasein mismo parece contener dentro de sí la posibilidad intrínseca de su dispersión fáctica y corporal. En este sentido, desde la lectura de Derrida en el Dasein de Heidegger estaría presente una especie de sexualidad pre-diferencial o pre-dual más originaria que no llevaría la marca binaria de la pertenencia a uno de los sexos. La neutralidad del Dasein, precisamente, que señala Heidegger, estaría mostrando no la ausencia de sexualidad sino que más bien el estado de indeterminación originario o pura posibilidad en el que se encuentra el Dasein. Esta postura se reafirma si consideramos que Heidegger acuña en el análisis de la existencia humana el concepto Dasein para referirse al ser humano y no las palabras alemanas Mensch o $M a n n^{5}$. Además como Escudero (2011) explica:

Dasein es el nombre técnico con el que Heidegger caracteriza la peculiar apertura $(D a)$ del ser humano al ser (Sein), y por tanto no debe comprenderse en términos de la existencia humana concreta ni tampoco en términos de un sujeto autónomo (p. 183). 
De manera que el concepto Dasein no se refiere a un existente concreto ya sea un hombre concreto o mujer concreta o una persona que profesa una religión determinada, sino que es la fuente originaria de la que emana toda posibilidad previa a cualquier determinación fáctica. Por tanto, esta ausencia de sexualidad del Dasein no es pura negatividad, al contrario, encierra una positividad originaria que permite la posibilidad de una concreción humana fáctica y elegida además en cada caso por el Dasein.

Ahora bien, respecto de la crítica de Sartre tenemos que situarla en el contexto del denominado "malentendido antropológico" entre el pensamiento de Heidegger y la primera recepción que hizo el existencialismo de su obra (Rodríguez Suárez, 2012). Este malentendido antropológico se debe a una interpretación de la analítica existencial del Dasein como una fundamentación antropológica. Cuando, en realidad, para Heidegger "la analítica del Dasein, como indica su nombre, es una determinada interpretación ontológica del ser humano como Dasein y esto al servicio de la preparación de la pregunta por el ser" (Heidegger, 2013, p. 199). La interpretación que Heidegger hace del ser humano en su analítica existencial es siempre en términos ontológicos y no ónticos, ya que su objetivo es mostrar el modo de ser del ser humano como Dasein y la intrínseca posibilidad que tiene de comprensión del ser. Por tanto, no se trata de una fundamentación antropológica o de una fundamentación ética sino de una analítica preparatoria en vistas de la pregunta que interroga por el sentido del ser.

El problema de Sartre radica en pasar por alto el significado ontológico de la analítica existencial de Heidegger. Además, ambos filósofos utilizan el término "existencia" en forma completamente diferente, ya que Sartre lo entiende en el sentido tradicional de existencia, por lo que su paradigma será el individuo o sujeto. Mientras que para Heidegger la existencia está referida al plano ontológico, es decir, al ser del ser humano, a las estructuras de su ser ${ }^{6}$. Como explica Heidegger, "la analítica del Dasein en cuanto existenciaria, es hablando formalmente una especie de ontología" (Heidegger, 2013, p. 196). Aunque la crítica de Sartre se esclarece por la interpretación errónea del proyecto ontológico de Heidegger, esta no ha sido la única que se ha detenido a atacar este aspecto en su pensamiento. De igual forma, Lévinas señalará en Totalidad e Infinito: "El Dasein en Heidegger jamás tiene hambre. El alimento no se puede interpretar como utensilio más que en un mundo de explotación" (Lévinas, 2002, p. 153). La crítica de Lévinas también va a cuestionar el aspecto fisiológico y corporal que parece ausente en el Dasein de Heidegger. Del mismo modo, Lévinas denunciará que la relación que tiene el Dasein con los entes del mundo es solo a partir de su manipulación y uso cotidiano, o sea instrumental, en tanto se presentan como útiles (Zeug) que están a la mano (Zuhandenes). A esta objeción se le sumarán más adelante otros filósofos como Plessner y Maurice Merleau-Ponty ${ }^{7}$.

Es un hecho que la pregunta por el cuerpo es excluida del proyecto de la ontología fundamental de Ser y tiempo, y esto ha sido constatado por muchos investigadores $^{8}$. Esto se ha traducido en una ausencia total de la pregunta por la diferenciación sexual del Dasein, el nacimiento y la vida del Dasein, y su intermediación corpórea en el encuentro con otros Dasein (Ciocan, 2008). Sin embargo, las reticencias de Heidegger para referirse al tema del cuerpo en Ser y tiempo tienen que situarse en el horizonte del análisis innovador que realiza de la existencia humana. Para Escudero (2011), gran parte de las críticas que se han hecho al "olvido del cuerpo" en la obra de Heidegger se fundan en el desconocimiento del propósito de Heidegger de superar la metafísica del sujeto y, en consecuencia, de lo que significa el concepto Dasein. Uno de los principales esfuerzos del proyecto heideggeriano consistirá en destruir lo que Derrida llamará luego "la metafísica de la presencia" (Derrida, 1989, p. 281), que se remonta al dualismo cartesiano mente-cuerpo. Desde esta metafísica el ser humano es concebido principalmente como presencia, es decir, como "sujeto" "yo" "conciencia". En este sentido, la metafísica del sujeto interpreta las cosas del mundo tales como: árboles, animales, personas, ideas, etc., en términos de substancia, vale decir, como algo que se mantiene inalterable en el tiempo. En desacuerdo con esto, Heidegger planteará que el ser humano ya no se puede pensar en términos de substancia sino como un ente que se caracteriza ontológicamente por su peculiar comprensión de su ser, y el ser en general. De manera que para Heidegger el ser humano tiene que ser caracterizado como Dasein, porque esto expresa la relación de apertura que tiene el ser humano al ser. Heidegger denominará esta peculiar precomprensión del estado de abierto del ser 
(Seinserschlossenheit) terminológicamente el "ahî" $(D a)$. Heidegger lo explica de la siguiente forma:

El Dasein no es tan solo un ente que se presenta entre otros entes. Lo que lo caracteriza ónticamente es que a este ente le va en su ser este mismo ser (...) el Dasein tiene en su ser una relación de ser con su ser. Y esto significa, a su vez, que el Dasein se comprende en su ser de alguna manera y con algún grado de explicitud (Heidegger, 2017, p. 37).

El término Dasein para Heidegger describe la constitución fundamental del ser humano, esto es, su modo de existir, que se caracteriza por la comprensión que tiene del ser en general, ya que a él mismo le va en su ser este mismo ser. Como explica Rivera "Dasein es el ente en cuyo ser se abre el $D a$, el ahí, para la manifestación del ser. El Dasein es el ente que está constitutivamente determinado por la comprensión del ser" (Rivera y Stuven, 2008, p. 49). Para Heidegger, en consecuencia, sería erróneo interpretar al ser humano como un ente que está-ahí (Vorhanden) porque el Dasein se caracteriza por su "tener que ser" $(\mathrm{Zu}$ sein). Si consideramos esto, podemos inferir que una interpretación heideggeriana del cuerpo (Leib) tendría que partir de la constitución fundamental del ser humano como Dasein, y por esta razón, el cuerpo (Leib) no podría ser concebido solo como algo simplemente presente (Anwesenheit). En este sentido, Heidegger explica "la presencia a partir de sí misma de una cosa es entendida ahí por su representacionalidad mediante un sujeto" (Heidegger 2013, p. 163). De acuerdo con Heidegger, la presencia (Anwesenheit) es concebida fundamentalmente como representatividad, es decir, como una forma de modificación del fenómeno. La presencia de los entes, entonces, es aprehendida exclusivamente como representacionalidad por un sujeto, porque el ente ya no se muestra desde sí mismo sino como algo que se contrapone a un sujeto pensante. Por lo mismo, el objetivo de Heidegger es desarticular esta concepción naturalista del cuerpo que opera en la psicología y en las ciencias naturales como presencia objetiva. El cuerpo (Leib) no puede ser objetivado solo como cuerpo físico (Körper), porque el cuerpo no se reduce a ser un hecho puramente biológico expuesto a leyes mecánicas y físicas. Para Heidegger la corporalidad (Leiblichkeit) del Dasein es esencialmente diferente a un estar sujeto a un organismo, porque el cuerpo se extiende más allá de la superficie de la piel, está activamente dirigido hacia el mundo, y se interrelaciona con los otros. El cuerpo (Leib) no es un objeto estático sino que deviene en su relación existencial con el mundo. Por esto, para Heidegger todo lo corporal presupone ya siempre al existir "todo lo que nombramos nuestra corporalidad hasta la última fibra muscular y hasta la más oculta molécula hormonal pertenece esencialmente al interior del existir" (Heidegger 2013, p. 338). Por tanto, la búsqueda del cuerpo en el horizonte del proyecto heideggeriano debe partir de la relación del cuerpo en su rol constitutivo de mundo, y de la interpretación del ser humano como Dasein sino se quiere perder de vista el significado ontológico que posee el cuerpo (Johnson, 2014a).

En los Seminarios de Zollikon Heidegger retomará la crítica de Sartre respecto de las escasas seis líneas que dedica al tema del cuerpo en Ser y tiempo. En los seminarios Heidegger responderá parcialmente a la crítica de Sartre objetando "El reproche de Sartre solamente puedo enfrentarlo con la afirmación de que lo corporal es lo más difícil, y que en aquel entonces no tenía nada más que decir al respecto" (Heidegger, 2013, p. 337). Las palabras de Heidegger son claras al señalar que en la época de Ser y tiempo él aun no tenía nada para decir acerca del fenómeno del cuerpo (Leibphänomen). Para Heidegger a diferencia de Nietzsche, el cuerpo es interpretado esencialmente como un fenómeno oscuro y difícil de abordar desde un análisis fenomenológico. En sus diálogos con Medard Boss, Heidegger responderá también parcialmente a las objeciones provenientes del campo de la fenomenología francesa replicando que los franceses solo poseen una palabra para referirse al cuerpo (le corps) y que, por esto, es muy difícil que ellos logren concebir la verdadera problemática del cuerpo. Además Heidegger insistirá en que aún no hay una descripción suficiente del fenómeno del cuerpo, que sea vista desde el existenciario ser-en-el-mundo (Heidegger, 2013). Lo que no significa que Heidegger niegue el valor de las investigaciones fenomenológicas del cuerpo sino que estas investigaciones no son relevantes para su ontología fundamental. La ontología fundamental de Heidegger sería más originaria que cualquier análisis concreto del cuerpo humano, debido a que la analítica existencial del Dasein describe las principales estructuras ontológicas existenciales de la existencia humana9 . Para Thomas Kessel (2014), por ejemplo, llevar a cabo un análisis 
fenomenológico del cuerpo humano requiere de un análisis previo de las estructuras ontológicas fundamentales del Dasein si no se quiere perder lo propio del ser cuerpo (Leibsein), es decir, su dimensión ontológica. En este sentido, se puede pensar que para Heidegger era fundamental aclarar primero la esencia del hombre desde la ex-sistencia (Ek-sistenz), en oposición a la interpretación metafísica del hombre como animal rationale, antes de iniciar alguna consideración respecto del cuerpo humano. Dicho de otro modo, para Heidegger no era viable emprender una fenomenología del cuerpo sin antes alcanzar el fundamento ontológico necesario para una interpretación adecuada del ser humano.

\section{EL CUERPO AUSENTE EN SER Y TIEMPO}

En los Seminarios de Zollikon Heidegger retomará la problemática del cuerpo excluida en Ser y tiempo, y se ocupará de este asunto más detenidamente. Sin embargo, hay que anticipar que estos seminarios no corresponden a un tratado sistemático de la corporalidad, ya que a menudo Heidegger se desvía del tema del cuerpo para referirse a otros asuntos como lo son el problema general de las ciencias, y el problema del método científico. Aun así, en los seminarios hay un esfuerzo de Heidegger por abordar otras temáticas diferentes del desarrollo de una ontología fundamental como ocurre en Ser y tiempo. Entre los diversos temas de los seminarios se encuentran, por ejemplo, la pregunta por el cuerpo, los estados de ánimo, las enfermedades psicosomáticas, la memoria, entre otros. En estos seminarios Heidegger pronunciará su propio planteamiento del cuerpo gestado a partir de sus lecturas de Nietzsche en el semestre del verano de 1939. En el transcurso de los seminarios Heidegger se encargará de demostrar que la noción de cuerpo que usan las ciencias médicas, en especial la psiquiatría y la psicología, se mueven dentro del paradigma cartesiano. Por esto, Heidegger intentará desarticular esta concepción naturalista del cuerpo como presencia objetiva y extensión espacio-temporal, que se caracteriza por interpretar el cuerpo como algo ahí presente, dicho de otro modo, lo que él denomina la Vorhandensein. Ahora bien, como ya señalamos en un comienzo para Heidegger lo fundamental en la investigación de lo corporal tiene que ver con la constitución del ser humano como Dasein. Para Heidegger siempre en toda experiencia de la corporalidad "se debe partir de la constitución fundamental del existir humano, es decir, del ser humano como Dasein" (Heidegger, 2013, p. 168). De lo anterior, es posible deducir que para Heidegger exista una estrecha correlación entre el modo de ser del ser humano como Dasein y el modo en que la corporalidad debería ser mostrada como fenómeno. Es admisible recordar que para Heidegger el ser humano como Dasein se haya siempre abierto para percibir la presencia del ente que nos interpela. $\mathrm{La}$ aperturidad del ex-sistir como Dasein es la que nos posibilita ser afectados corporalmente, y en consecuencia, tener algo así como un cuerpo físico. Esta forma de razonar explica que Heidegger luego afirme que "El corporar pertenece al ser-en-el-mundo el cual es la comprensión primaria de ser. Por ello, esta no es algo que se añada después al corporar" (Heidegger, 2013, p. 291). En el corporar se hace manifiesto el ente que nos interpela pero para que este ente nos sea donado en su significatividad es necesaria una primaria comprensión de ser, y una aperturidad para que comparezca en nuestro ser-enel-mundo. La constitución fundamental del Dasein como ser-en-el-mundo (In-der-Welt-sein) implica que el ser humano se encuentra siempre instalado ya en un espacio de relaciones y significados siendo afectado. Por esto, desde la opinión de Heidegger una fenomenología del cuerpo tendría que arrancar primero del desarrollo de este existenciario, ya que como él insiste "El tratamiento de los fenómenos del cuerpo es completamente imposible sin un desarrollo suficiente de los fundamentos del existenciario ser-en-el-mundo" (Heidegger, 2013, p. 240). De ahí que Heidegger se excuse en que es necesario volver a su ontología fundamental y desarrollar el existenciario ser-en-el-mundo si quiere abordar ahora el fenómeno del cuerpo.

Para Heidegger hay que entender el cuerpo desde su pertenencia a la estructura de la existencia humana (Dasein), y esta debe ser entendida como guardar relación con lo que hay, es decir, como una estructura de relacionalidad. Para Heidegger la existencia no tiene nada que ver con lo que en psicología o psicopatología se denomina psique, sujeto, o conciencia, sino que su propuesta es entender la existencia humana como Dasein o seren-el-mundo (In-der-Welt-sein). Para aclarar a qué se refiere Heidegger con esta formulación él explicará en los seminarios que "el estar-en-el-mundo nunca es una propiedad de una subjetividad de cualquier forma representada, sino que es de antemano el existir del ser humano mismo" (Heidegger, 2013, 
p. 330). En este sentido, el ser humano como Dasein no existe como algo que esté ahí simplemente presente (Vorhanden) ni como un objeto sino que se caracteriza por su apertura al ser, por su peculiar comprensión de ser, y por estar abierto a un ámbito que consiste en poder percibir las significatividades de las cosas que le son dadas. Para desarrollar esta idea de relacionalidad propia del modo de ser como Dasein Heidegger comenta el siguiente ejemplo:

\begin{abstract}
El "estar en medio", que entre otros indica el hacer-presente es fundamentalmente diferente del estar-ahí, por ejemplo, de los zapatos que colocamos frente a la puerta del cuarto (...) Este "estar junto a" significa aquí la proximidad espacial de las cosas. Por el contrario, el "estar en medio" de nuestro estar-aquí en medio de las cosas tiene el rasgo fundamental del estar-abierto para lo presente (Heidegger, 2013, p. 127).
\end{abstract}

Desde la perspectiva de Heidegger "el estar-abierto" para lo presente es el rasgo fundamental del ser humano como Dasein. En otras palabras, Heidegger señalará que nuestra relacionalidad es precisamente aquello que permite que seamos y que lo demás comparezca. Podríamos decir entonces que los zapatos están junto a la puerta pero aquí el "estar junto a" solo exhibe una relación espacial entre dos cosas presentes. Mientras que el "estar en medio", rasgo propio del Dasein, permite hacer manifiesta la puerta en tanto puerta, es decir, reconocerla en tanto ente dotado de contenido significativo y ser afectados por ella. Además, en el "estar junto a" en el caso de la puerta y de los zapatos mienta a dos entes simplemente presentes en diferentes lugares en el espacio, sin estar necesariamente afectados el uno por el otro. Ahora bien, la forma en que el Dasein se encuentra en el espacio para Heidegger es totalmente diferente a un ente que está ahí (Vorhanden) y que ocupa un lugar determinado en el espacio. Justamente, el Dasein como ser-en-elmundo se encuentra ya dispuesto en un espacio de relaciones en el que está siendo interpelado por los entes. En este contexto, es razonable preguntarse ahora: ¿Cómo se encuentra el ser humano como Dasein en el espacio en tanto él corpora? ¿Cómo se relaciona lo corporal con el espacio? A partir de estas interrogantes se tiene que llevar a cabo la tarea de dilucidar el fenómeno del cuerpo, ya que por lo visto estaría estrechamente vinculado con el modo en que el Dasein se encuentra en el espacio. Esta relación entre la espacialización del Dasein y la corporalidad es un antecedente que ya encontramos planteado en Ser y tiempo "la espacialización del Dasein en su corporalidad que implica una problemática propia que no ha de ser tratada aquí" (Heidegger, 2017, p. 136). La sentencia de Heidegger excluye finalmente el tema del cuerpo en Ser y tiempo argumentado que no es algo que ha de ser estudiado en su ontología fundamental. En los Seminarios de Zollikon Heidegger volverá al tema del cuerpo para señalar que "no comprendemos el fenómeno del cuerpo, puesto que aún no comprendemos el fenómeno del espacio" (Heidegger, 2013, p. 368). Para Heidegger parece ser relevante aclarar primero el modo en cómo concebimos el espacio antes de iniciar cualquier consideración del fenómeno del cuerpo. Por esto, resulta necesario volver a revisar el $\S 23$ de Ser y tiempo, donde Heidegger desarrolla la espacialidad del estar-en-el-mundo ahora en vistas de aproximarnos al fenómeno de la corporalidad (Leiblichkeit).

\section{LA ESPACIALIDAD(RÄUMLICHKEIT) DEL DASEIN}

El trabajo de rastrear el lugar del cuerpo en la analítica existencial del Dasein tiene que comenzar por medio de una investigación completa que esté enfocada en los pasajes, escasos pero precisos, que esbozan el tema del cuerpo en Ser y tiempo. Aunque el cuerpo es eliminado de la ontología fundamental de Ser y tiempo es posible encontrar algunos antecedentes que más tarde le permitirán a Heidegger pronunciar su propio planteamiento del cuerpo en los seminarios. Para Ciocan (2008), la noción del cuerpo en Heidegger se puede rastrear entre los rincones y grietas de la analítica existencial del Dasein. El autor argumenta que a partir de varios pasajes de Ser y tiempo es posible deducir el papel implícito que desempeña el cuerpo tanto en la explicitación como en la construcción de algunos conceptos claves. El ejemplo más representativo de esto lo constituye el binomio Vorhandenheit y Zuhandenheit, donde todo aquello que implica la imagen de la mano (Hand) es indispensable para entender el sentido de ambos conceptos (Sanz Peñuelas, 2017). Ciocan (2008), sugiere que es perfectamente razonable pensar que el cuerpo juega un papel fundamental en Ser y tiempo, no solo por la interacción entre el Dasein y el mundo sino por la disposición originaria del mundo. Siguiendo esta misma argumentación en algunos parágrafos de Ser y tiempo se encuentran 
algunas referencias, más o menos al azar, acerca del cuerpo. En la espacialidad del Dasein ( $\$ 22$, 23 , y 24. de Ser y tiempo) es precisamente donde el fenómeno del cuerpo recibe más atención en la analítica existencial del Dasein. Este análisis que realiza Heidegger de la espacialidad del Dasein se lleva a cabo a partir de tres momentos. En el primer momento Heidegger analiza la espacialidad de lo a la mano dentro del mundo (\$22) que incluye a los entes y los objetos del mundo circundante. En el segundo momento (\$23) Heidegger se ocupará de analizar la espacialidad del ser-en-el-mundo, para finalmente en el tercer momento, analizar la espacialidad del Dasein y el espacio como tal (\$24). En la espacialidad del ser-en-el-mundo Heidegger se refiere brevemente a la espacialización del Dasein en su corporalidad (Leiblichkeit). Sin duda, este es el reconocimiento ontológico más alto que el cuerpo recibe en Ser y el tiempo, a saber, la de contribuir a la espacialización del Dasein, la de ocasionarla, la de determinarla, producirla (Ciocan, 2008). El cuerpo parece estar subordinado a la estructura de la espacialidad que, a su vez, está subordinada a la estructura del "estar-en" (In sein). Por esta razón, Heidegger será reiterativo en los seminarios al argumentar que "todo existir, nuestro comportamiento, es necesariamente corporal, pero no solamente. Es en sí corporal. Solo que antes se debe determinar el existir como referencia al mundo" (Heidegger, 2013, p. 301). Para Heidegger existir consiste fundamentalmente en un estar-en-el-mundo aunque no todo lo que existe se encuentra de igual forma en el espacio. En Ser y tiempo, Heidegger aclara que el Dasein "está-en" el espacio de modo distinto a como "están-en" el mundo los objetos presentes en el espacio. El Dasein mismo es espacial en su estar-en-el-mundo pero este "estar en el espacio" del Dasein debe ser determinado a partir del modo de ser de este ente. Desde la postura de Heidegger "la espacialidad del Dasein el cual por su misma esencia no es un estar-ahí no puede significar un encontrarse en alguna parte dentro del espacio cósmico" (Heidegger, 2017, p. 132). Hay que comprender que la espacialidad del Dasein para Heidegger tiene que ser entendida siempre en términos ontológicos, y por esto, no puede ser determinada ónticamente como un estar-ahí en algún lugar del espacio. El Dasein mismo tiene su propia forma de estar en el espacio que solo es posible sobre la base de la estructura existencial del estar-en-el-mundo. Por esto, es necesario aclarar primero el momento

constitucional del "estar-en" como tal para sacar a la luz la constitución ontológica fundamental del fenómeno del estar-en-el-mundo. Heidegger explicará que la expresión compuesta estar-en-el-mundo, como ya lo muestra su formulación, es un fenómeno unitario y originario. Lo anterior no impide que para Heidegger el estar-en-el-mundo esté articulado sobre la base de tres momentos estructurales constitutivos: 1. en-el-mundo, 2. El ente, y 3. El estar-en. En el primer momento en-el-mundo Heidegger investiga la estructura ontológica del mundo y determina la idea de la mundaneidad como tal. En el segundo momento, Heidegger analiza el ente que existe en forma del estar-en-el-mundo, es decir, acerca de quién es este ente en su cotidianeidad. En el tercer momento, Heidegger se pregunta por el "estar-en" que es constitutivo del ser del Dasein y que lo sitúa en medio de las cosas del mundo. Para entender esto, el término "estar-en" se refiere a un existenciario cuyo sentido para Heidegger se hace visible recurriendo a su etimología:

\begin{abstract}
El alemán in procede de innan-, que significa residir, lo que en latín se dice habitare: permanecer, quedarse en, por su parte, an se relaciona con estar acostumbrado, familiarizado con; tiene la significación de colo, en el sentido de habito y diligo, esto es, ocuparse con una cosa, estar en ella y con ella (Heidegger, 2017, p. 82).
\end{abstract}

Con esta explicación Heidegger establece los distintos modos en que los seres humanos y las cosas están en el espacio, ya que la metafísica tradicional ha concebido al ser humano solo como un ente que está ahí (Vorhandenheit). Mientras que para Heidegger el modo de ser del ente que no tiene el carácter del Dasein que se caracteriza por este "estar-en". Heidegger lo explica de la siguiente forma:

\begin{abstract}
Nos inclinamos a comprender este "estar-en" como un estar "dentro de". Con este término se nombra el modo de ser de un ente que está "en" otro a la manera como el agua está "en" el vaso y el traje "en" el armario (Heidegger, 2017, p. 82).
\end{abstract}

Para Heidegger resulta evidente que el agua y el vaso así como el traje y el armario, tienen todos los modos de ser del "estar-ahî", esto es, del estar juntos a otros entes que están en un lugar ocupando un mismo espacio. El "estar-en" refiere siempre a 
cosas que están en una relación de proximidad espacial. Con el "en" Heidegger señala la extensión en el espacio que tienen los entes entre sí respecto del lugar que ocupan. Pero el "estar-en" otro ente que está-ahí para Heidegger en el sentido de una relación de lugar, son caracteres que pertenecen al ente que no tiene el modo de ser del Dasein (Heidegger, 2017, p. 82). A partir de esto se esclarece entonces que el modo de ser del Dasein no tiene la forma del simple estar-ahí, como presencia (Vorhandenheit) y que su relación con el espacio se funda en una constitución ontológica existencial. El modo de estar de un objeto que ocupa un lugar en el espacio es radicalmente diferente de la espacialidad del Dasein. El Dasein mismo abre espacios y esto se torna en condición de posibilidad para el surgimiento significativo de los entes. Por esta razón, lo que caracteriza el modo de ser del Dasein es fundamentalmente su aperturidad hacia los entes y que su espacialidad está fundada en la constitución ontológica del mundo concebido como horizonte de significación. En palabras de Heidegger:

El estar-en mienta una constitución de ser del Dasein y es un existencial. Pero entonces no puede pensarse con esta expresión en el estarahí de una cosa corpórea (...) El estar-en no se refiere a un espacial estar-el-uno-dentrodel-otro de dos entes que están-ahí, como tampoco el "en" originariamente significa en modo alguno una relación espacial de este género (Heidegger, 2017, p. 82).

Para Heidegger el Dasein al tener la estructura ontológica existencial del "estar-en" habita un mundo, es decir, está ocupado y absorbido al estar en medio de las cosas. El Dasein no tiene el modo de ser del estar-ahí como una cosa que está junto a otra dentro de un espacio geométrico. En suma, el "estar-en" no remite nunca a una proximidad espacial entre dos entes sino que expresa la manera en que habitamos el mundo inmediato. Y habitar para el Dasein significa moverse entre las cosas, pero no solo moverse, sino que moverse con familiaridad como quien conoce a la perfección esas cosas y las tiene presentes (Sanz Peñuelas, 2017). El Dasein es el único ente al que le está dado un mundo, y por lo mismo, el Dasein puede perderse entre las cosas que comparecen dentro de su mundo inmediato. Desde el análisis que realiza Heidegger se nos revela el profundo significado ontológico que posee la espacialidad del Dasein, en tanto ente que espacia
(Räumen), es decir, que abre espacios habitando en un mundo de relaciones y significados.

\section{LA ESPACIALIDAD DEL CUERPO (LEIB)}

Como ya fue expuesto anteriormente, la espacialidad de Dasein (Räumlichkeit) no tiene que ver con un espacio físico cuya imagen sea la de un contenedor donde se sitúa todo lo presente. Tampoco el espacio puede ser concebido como un vacío originario donde se sitúan las cosas y posteriormente el Dasein. Para Heidegger esto equivaldría a una determinación óntica donde la relación espacial entre los entes tendría un carácter mensurable o medible propio del espacio físico-geométrico. En cambio, como sostiene Sanz Peñuelas (2017), la espacialidad del Dasein se relaciona con una distribución pragmática del entorno más que con la posición objetiva de un punto en un plano de coordenadas. Por tanto, la espacialidad del Dasein se relaciona con la forma en que nos ocupamos (Besorgen) de las cosas y no con la distancia que se mide entre unas y otras en un plano tridimensional de posición. El ejemplo que cita Heidegger en Ser y tiempo respecto de las gafas parece iluminar esta forma de concebir el espacio. Para quienes usan lentes, dirá Heidegger, el cuadro que se contempla está a una distancia menor que los lentes mismos que se tienen incluso sobre la nariz, y por medio de estos se puede admirar mejor la pintura. Con esto Heidegger quiere demostrar que la medición de las cosas que están en el espacio no está dada por una medición objetiva y contable, sino que por lo que él denomina la ocupación (Besorgen). El Dasein en tanto estar-en-el-mundo, esto es, en cuanto familiar habérselas con lo que comparece dentro del mundo no mide primariamente las distancias de acuerdo con un determinado sistema de unidades, sino que lo hace en función de sus iniciativas personales y tendencias prácticas (Sanz Peñuelas, 2017, p. 120). En este sentido, la espacialidad del Dasein no consiste en encontrarse en algún lugar dentro del espacio o un estar a la mano del lugar propio, ya que para Heidegger "el Dasein del ser humano es espacial en sí, en el sentido de instalar el espacio y de la espacialización del Dasein en su corporalidad" (Heidegger, 2013, p. 139). Para Heidegger el rasgo fundamental que diferencia el modo de ser espacial del Dasein es el in-volucramiento, es decir, el estar ocupado con las cosas del mundo y abierto para la presencia de los entes. La apertura de la existencia 
tiene este carácter espacial pues "el existir como Dasein significa el mantener abierto un ámbito que consiste en poder percibir las significaciones de las cosas que le son dadas y que lo interpelan a partir del despejamiento de este" (Heidegger, 2013, p. 30). Si consideramos que el Dasein siempre se encuentra abierto para percibir la presencia del ente, pensar la corporalidad como una estructura mecánica o físico-química sería totalmente equivocado. Por el contrario, la corporalidad entendida como un modo de ser del Dasein nos situaría de entrada en una relación de significados con los entes (Rodríguez Suárez, 2012). Para Heidegger "ser corporal no quiere decir que al alma le esté añadida una masa llamada cuerpo, sino que en el sentirse el cuerpo está de antemano contenido en nuestro sí-mismo" (Heidegger 2000a, p. 102). En la interpretación de Heidegger al vincular el cuerpo a la existencia lo lleva a apartarse de toda interpretación biológica y naturalista, y por consiguiente, de la idea de organismo animal ${ }^{10}$. Para Heidegger el cuerpo ha sido previamente malinterpretado solo como cuerpo físico (Körper) y se pierde, por tanto, su dimensión ontológica existencial. En los seminarios Heidegger lo ilustra de la siguiente forma:

No podemos ver porque tenemos ojos, más bien solo podemos tener ojos porque somos seres que ven según su naturaleza fundamental. Así tampoco podríamos ser corporales (...) si nuestro ser-en-el-mundo no consistiera en su fundamento ser un siempre ya ser-referido perceptivo a aquello que se dirige a nosotros desde lo abierto de nuestro mundo, abierto con el cual existimos (Heidegger, 2013, p. 339).

De lo anterior se concluye que para Heidegger el ver no tiene que ver solo con la percepción de los ojos del cuerpo, sino que también habría un ver más fundamental en sentido existencial, en el que está fundado el ver sensible y que permite hacer manifiesto al ente que comparece. En este ver en sentido existencial habría una aprehensión no sensible del ente que está-ahí, porque el Dasein como ser-en-el-mundo implica ya siempre un poder percibir algo que se nos desencubre y un estar orientado hacia algo. Acerca de esta orientación explica Heidegger:

Solo gracias a tal orientación esencial de nuestro Dasein, podemos diferenciar un enfrente y un atrás, un arriba y un abajo, un izquierdo y un derecho (...) Pero no somos primero corporales y luego a partir de ello tenemos un enfrente y un atrás (Heidegger, 2013, p. 339).

Para Heidegger solo gracias a esta orientación del Dasein (aquello que Husserl llamará intencionalidad de la conciencia y Heidegger aperturidad), que se funda en la espacialidad es posible pensar la corporalidad: "el Dasein no es espacial porque sea corporal sino que la corporalidad solamente es posible porque el Dasein es espacial en el sentido de instalador" (Heidegger, 2013, p. 139). Hay que tener en cuenta que para Heidegger la espacialidad no es un modo de ser derivado de la corporalidad del Dasein ni tampoco está fundada en la constitución física del cuerpo. El estar en el espacio para el Dasein implica un moverse con familiaridad entre las cosas del mundo y un conocimiento tácito de los entes del mundo cotidiano. El poder reconocer estos entes para Heidegger se relaciona con la constitución del Dasein como estar-en-el-mundo, y con la estructura de la existencia entendida como una estructura primaria de precomprensión. Para Heidegger solo porque ya siempre nos encontramos arrojados en un mundo es que podemos luego orientarnos. Por esto, la direccionalidad y la des-alejación del Dasein están fundadas sobre la base del estar-en-el-mundo.

Ahora bien, como ya se planteó en un comienzo la pregunta por el cuerpo está referida originariamente a la pregunta por el espacio. En este contexto, es preciso preguntarse entonces si la corporalidad (Leiblichkeit) al igual que la espacialidad (Räumlichkeit) del Dasein podría ser considerada como una estructura existencial del Dasein. Para Heidegger la existencia humana (Dasein) se despliega como un vivir que es un estar-en-el-mundo corporalmente. Por esto, el vivir del ser humano no puede ser pensado separado de un vivir necesariamente corporal, ya que el cuerpo no es algo que simplemente se tiene y que podamos dejar al margen al momento de experienciar el mundo. Como dirá Heidegger en sus lecturas concernientes a Nietzsche:

No tenemos un cuerpo (Leib) como llevamos una navaja en el bolsillo; el cuerpo tampoco es simplemente un cuerpo físico (Körper) que nos acompaña y del que constatamos, expresamente o no, que está también allí delante. No tenemos un cuerpo (Leib) sino que somos corporales (leiblich). (Heidegger 2000a, p. 102). 
Heidegger cambia la perspectiva de "tener un cuerpo" como se tiene cualquier objeto físico por "ser un cuerpo" para realzar la dimensión ontológica y vivencial de la corporalidad en tanto pertenece a un modo de ser del Dasein. El cuerpo no se tiene como un ente más, debido a que siempre lo vivo en cada como "mío" (Heidegger, 2013, p. 148). En este sentido, el cuerpo se constituye en un aspecto fundamental del existir, ya que necesariamente somos un cuerpo al ser seres sintientes que se encuentran condicionados por el tiempo y el espacio. Para Heidegger si nosotros tenemos un cuerpo es debido a que nuestra existencia ya es en sí corporal, porque está abierta hacia el mundo donde comparecen los entes. Para Ciocan (2008), es gracias al cuerpo que el Dasein se posiciona en lo abierto, porque el cuerpo es el lugar donde ocurre el acontecimiento del existir y donde se da a lugar al gozar, sufrir, nacer, morir, etc. En este sentido, vivir corporalmente en un mundo quiere decir ex-sistir en un espacio, estar abierto a los entes, y a los otros para ser afectado. Esto explica que para Heidegger toda experiencia de lo corporal se deriva de la constitución del ser humano como Dasein:

Pues bien, todo lo que nombramos nuestra corporalidad hasta la última fibra muscular y hasta la más oculta molécula hormonal, pertenece esencialmente al interior del existir, (...) es un ámbito de este poder-percibir no objetivable, no visible ópticamente de significatividades de lo que comparece en lo que consiste todo Dasein (Heidegger, 2013, p. 338).

Sobre la cita anterior podemos desprender dos aspectos que son bastante claros. Por una parte, el Dasein en su estar-en-mundo como tal es corporal y no existe experiencia del cuerpo que no evoque ya una apertura de mundo. Por otra parte, este poder-percibir no objetivable en que consiste el Dasein y en donde acontece la corporalidad tiene que ver también con un régimen de actividad espacial del Dasein. Por tanto, podríamos presuponer inicialmente que la espacialidad y la corporalidad podrían ser dos caras de una misma moneda. Pensemos, por ejemplo, en lo que los neurocientíficos denominan como "parálisis de sueño". En medio del trance del sueño nos despertamos y nos percatamos que no podemos mover nuestro cuerpo o efectuar cualquier tipo de movimiento voluntario. Aunque nos vemos limitados por nuestro cuerpo al no poder movernos, en ningún momento somos privados de nuestra espacialidad. En el transcurso del trance sabemos que estamos tendidos en la cama y que a un costado de la cama hay una mesa de noche junto a una lámpara. Como indica Sanz Peñuelas (2017), si por algún motivo perdemos la posibilidad efectiva de actuar en nuestro entorno, esto no significa que para mí la espacialidad pierda su actualidad estructural. Lo anterior se explica porque nos encontramos en un mundo ya dado de antemano y experimentamos el episodio de la parálisis no como una pérdida de la espacialidad sino que la espacialidad se hace más patente que nunca. En este sentido, nuestro campo perceptivo tiene una directa relación con nuestra corporalidad, por lo que podrían concebirse ambas como estando en una relación de dependencia mutua. Pero para Sanz Peñuelas (2017) resulta imposible conceder la supremacía a uno de los dos ámbitos, ya que siguiendo las enseñanzas de Heidegger ninguno podría estar por encima del otro, pues ambos están en pie de igualdad por lo que respecta a su grado de originariedad.

En suma, esta primera aproximación al cuerpo nos mostró que la espacialidad del Dasein está en estrecha relación con la corporalidad. El cuerpo (Leib) no se tiene a la manera en que se tiene un cuerpo físico (Körper) que ocupa un lugar en el espacio, ya que acontece en la aperturidad del ex-sistir, en el "Ahí" del Dasein, y en la comprensión primaria de ser. De manera que el cuerpo se presenta como codeterminante del ser-en-elmundo del Dasein, en cuanto se muestra como la apertura misma "el corporar está codeterminado por mi ser-humano en el sentido de la estancia extática en medio del ente despejado" (Heidegger, 2013, p. 147). Aunque Heidegger hace patente la dimensión ontológica del cuerpo, esto no significa necesariamente que el ser tenga una dimensión corporal. Tal como se expuso en un comienzo la concepción heideggeriana del cuerpo busca apartarse de toda interpretación naturalista o biológica del cuerpo ${ }^{11}$. Por esto, es importante preguntarse $\mathrm{y}$ analizar algunas interrogantes que surgen desde el planteamiento de Heidegger acerca del cuerpo. Pensar, por ejemplo, si es posible concebir un cuerpo al margen de un sujeto corporal o si se puede prescindir del todo de la constitución física y material del cuerpo, como ocurre en Heidegger en el que cuerpo parece tener un carácter derivado del existenciario ser-en-el-mundo. 


\section{EL CUERPO AMBIGUO}

Para comenzar hay que señalar que el cuerpo (Leib) no se deja explicar en el planteamiento heideggeriano por la tradicional dicotomía alma-cuerpo, pues según Heidegger, "soma y psique no son al ser humano como el rojo y el verde son al color, porque sique y soma no son dos formas diferentes del ser humano genérico" (Heidegger, 2013, p. 293). En otras palabras, el rojo y el verde son variaciones del color pero soma (cuerpo) y psique no pueden ser variaciones del ser humano. Para Heidegger si hablamos de dos regiones diferentes del ser humano es porque lo hacemos de manera cósica, lo que significa que tal diferenciación es ontológicamente errónea. Este error para Heidegger puede ser salvado solo si hay una superación crítica de la escisión sujeto-objeto, para que el cuerpo (Leib) pueda ser experienciado a partir de la estructura existenciaria del ser-en-el-mundo y asumido como un rasgo del Dasein, es decir, como un existencial. En este sentido, el cuerpo (Leib) aparece como codeterminante del ser-en-el-mundo "El corporar pertenece como tal al ser-en-el-mundo. Pero el ser-en-el-mundo no se agota en el corporar" (Heidegger, 2013, p. 244). De lo anterior, es evidente que para Heidegger el corporar se deja aprehender a partir del ser-en-elmundo, pero fuera de este existenciario no habría cuerpo como ocurre con el animal (Benoist, 1994, p. 116). Recordemos que para Heidegger "este vivir corporalmente es algo esencialmente diferente del mero estar sujeto a un organismo" (Heidegger, 2000b, p. 103). El cuerpo en el que está pensando Heidegger es, en esencia, un cuerpo desprendido de su materialidad, o si se quiere, un cuerpo para quien su materialidad no es relevante y que por lo mismo, este cuerpo no puede ser homologado a la corporalidad animal. En Carta sobre un Humanismo, Heidegger nos advierte que de entre todos los entes el ser vivo es el que más nos resulta difícil de ser pensado, pues es el más afín a nosotros, aun cuando está separado de nuestra esencia ex-sistiendo por un abismo (Heidegger, 2000b, p. 32). Aunque para Heidegger compartimos características similares con los animales, entre el existir y la vida animal, hay un abismo infranqueable. Se trata para Heidegger de dos modos radicalmente diferentes de ser. Lo propio del ser humano es el estar abierto para el darse libre de los entes por su constitución fundamental como Dasein. En cambio, el comportamiento del animal está determinado por lo que Heidegger denomina en las lecciones del 1929/30 respecto de los conceptos fundamentales de la metafísica, por un "conducirse" (sich benehmen) y por un hacer o empujar (treiben) de sus impulsos ${ }^{12}$. De modo que el animal es conducido por los impulsos que le son propios, y por esto, no puede acceder al ente con independencia a él o concebirlo como totalidad. Recordemos que para Heidegger el animal es concebido fundamentalmente como pobre de mundo (das Tier ist weltarm), es decir, el animal abre mundo cerrándolo. Para Heidegger el animal se encuentra cautivado en sí mismo, ya que el conducirse del animal es un permanecer en sí, es un estar preso en sí, sin reflexión. Dicho de otro modo, el animal se encuentra encerrado en un anillo, que es su medio circundante, en el que se halla cautivado en sí (Heidegger, 2007, p. 291). Ahora bien, esto explica que para Heidegger la corporalidad del Dasein tenga que ser vista desde su esencia como ex-sistiendo, mientras que la corporalidad animal está estrechamente vinculada con su anillo circundante. El anillo circundante (Umring), como lo denomina Heidegger, es el rasgo principal de la esencia de la animalidad y pertenece a la organización y estructura morfológica más interna del animal. Como explica Buchanan:

"Heidegger's note that this encircling is due
to the animal's morphology further confirms
that this ring around the animal does not solely
belong as an environmental construction that
the animal produces, but as an inherent structure
rooted within the morphological development
of the animal itself" (Buchanan, 2008, p. 95).

Heidegger recurre a las investigaciones biológicas de Buytendijk y, más específicamente, de Uexküll, para afirmar que la morfología de cada animal ya abarca el entorno dentro de él. Para Heidegger "el conjunto del organismo en cierta manera se identifica con la superficie de la corporalidad animal" (Heidegger, 2007, p. 317). En este sentido, el medio ambiente ya se encuentra contenido en la morfología del cuerpo del animal, pues los impulsos que determinan la conducta del animal responden a un medio ambiente determinado. Por tanto, lo que hace Heidegger es borrar el límite de la superficie del cuerpo animal, y en cambio, redibuja la unidad del animal como una que ya contiene el medio ambiente dentro la morfología de su cuerpo (Buchanan, 2008). Las conclusiones de Heidegger acerca de la esencia de la animalidad lo 
llevan finalmente a afirmar una estructura relacional entre el organismo animal y su medio ambiente, que constituyen la morfología de su cuerpo. Para así contraponer este planteamiento con la conocida tesis que "el ser humano es constructor de mundo" (der Mensch ist weltbildend), lo que le permitiría mayor acceso a los entes, es decir, experimentarlos y tener una relación significativa con ellos, y esto se vería reflejado en su comportamiento al no estar determinado por completo por los impulsos o instintos.

Ahora bien, cuando Heidegger habla de la corporalidad del Dasein parece prescindir por completo de la constitución física y del aspecto material del cuerpo, ya que como él mismo ejemplifica: "Precisamente cuando estoy absorbido con cuerpo y alma en una cosa, el cuerpo (Leib) no está. Pero este no estar del cuerpo (Leib) no es una nada, sino uno de los fenómenos más misteriosos de la privación" (Heidegger, 2013, p. 145). Este "no estar del cuerpo", precisamente, revela que el corporar (Leiben) no está fundado en la constitución física del cuerpo sino que refiere para Heidegger a nuestra ocupación práctica con las cosas, a un régimen de actividad pragmático derivado de nuestro modo de ser como Dasein $^{13}$. Esta ambigüedad de lo corporal en Heidegger al intentar pensar un sujeto corporal al margen de la constitución física del cuerpo se ratifica cuando sostiene "el límite del cuerpo (Körper) nunca llega a ser un límite del cuerpo (Leib) por el hecho de que aparentemente se empalme con el límite del cuerpo (Leib)" (Heidegger, 2013, p. 147). Para Heidegger el cuerpo visto ontológicamente excedería los límites del cuerpo físico (Körper), por lo que su actividad no terminaría en los límites de la materialidad del cuerpo, sino que coincidiría con la donación de los contenidos significativos de los entes, ya previamente determinado por la comprensión de ser. Dicho de otro modo, el corporar para Heidegger está determinado por el ex-sistir del ser humano, al encontrarse en el claro del ser y abierto para la presencia del ente. El corporar estaría fundado en el corresponder, pero el cuerpo (Leib) es la condición necesaria pero no suficiente para la referencia (Heidegger, 2013, p. 274). A diferencia de Merleau-Ponty, para quien no hay una existencia desencarnada en la que el cuerpo sería una mera manifestación, el cuerpo para Heidegger solo tendría razón de ser porque a la existencia como tal le corresponde abrir mundo habitándolo. Si el ser humano como Dasein no consistiera ya en un estar en medio del claro del ser y abierto para el ente, no habría condición suficiente para tener un cuerpo, pues nuestro cuerpo está previamente determinado por la apertura de la existencia y por la comprensión de ser. Para Heidegger, por ejemplo, nuestra relación con la luz de una vela no es de inmediato corporal. Heidegger nos dice que la luz de vela no muestra nada por sí misma y que el ser humano ve lo que se muestra en el resplandor de la vela solo en la medida en que él está ya en lo despejado (Heidegger \& Fink, 2018, p. 185). La apertura para la luz en general es lo que le permite al ser humano ver algo en el resplandor de la vela y percibir esos atributos sensibles. El cuerpo aquí es concebido como la posibilidad de desplegar al ente que es comprendido a partir de una relación con él. En síntesis, el cuerpo tendría para Heidegger un carácter secundario o accesorio si se quiere, pues es condición necesaria pero no suficiente, porque el corporar estaría sujeto a la estructura existenciaria del ser-en-el-mundo y finalmente a la aperturidad de la existencia.

\section{CONCLUSIÓN}

A modo de conclusión me gustaría mencionar dos aspectos que me parecen relevantes y que se desprenden de la discusión anterior acerca del lugar del cuerpo en la otología fundamental de Heidegger, así como sus alcances y limitaciones.

a) En primer lugar como se expuso anteriormente el corporar para Heidegger está determinado por el modo de ser del ser humano como Dasein, ya que este corporar acaece en la aperturidad de la existencia. El corporar (Leiben) es una posibilidad propia de la existencia humana aunque fundada en la aperturidad de la existencia misma. Por esto, el cuerpo para Heidegger sería condición necesaria pero no suficiente porque el corporar tiene que ser concebido como un fenómeno dependiente del existenciario ser-en-el-mundo, y que se funda al mismo tiempo en lo previamente abierto por la existencia. Para Heidegger si el ser humano como Dasein no consistiera ya en un "ser concernido" (Angesprochensein) por el ser no podríamos tener algo así como un cuerpo. El cuerpo desde el plano ontológico de Heidegger prescindiría de la constitución física y excedería al mismo tiempo los límites de su materialidad. La forma en que se presenta el corporar para Heidegger acontecería en la comparecencia de los entes y la donación de sus contenidos significativos. Por lo que en todo 
corporar ya hay siempre, como señala Heidegger, una primaria comprensión de ser. Ahora bien, esta forma de pensar el cuerpo conduce finalmente a Heidegger a una ambigüedad de lo corporal en la que se intenta mostrar el aspecto material de la existencia sin estar impregnada esta de substancia corporal. Como señala J. Benoist (1994), en cuanto el cuerpo posee un carácter ontológico solo puede descubrirse mediante una "des-corporeización del ser", esto es, en tanto Heidegger lleva a cabo una ruptura con la metafísica como presencia corporal (p. 115). Si bien es cierto que Heidegger logra apartarse de la concepción cósica del cuerpo como mera presencia objetiva (Anwesenheit) para situarlo en el plano ontológico, esto no elimina la dificultad de considerar si es plausible pensar el cuerpo al margen de su constitución física o descartar de plano la influencia de la materialidad. Lo que sin duda será puesto de manifiesto por otras fenomenologías del cuerpo como la de Jean-Luc Nancy o Michel Henry ${ }^{14}$. Sin embargo, el valor del planteamiento heideggeriano reside en pensar el cuerpo evitando caer en reduccionismos biológicos que lo instala, sin desearlo o no, en una ambigüedad de lo corporal al posicionarse desde la perspectiva del ser. De igual forma, la búsqueda de Heidegger por pensar el cuerpo más allá del dualismo cartesiano que considera al hombre como un compuesto de alma y cuerpo, lo lleva a pensar al ser humano desde una mirada ontológica más amplia e integral que ve al ser humano como totalidad (Dasein) y no como un agregado de partes.

b) En segundo lugar desplegar el cuerpo como un modo de ser del Dasein asi como lo hace Heidegger en los seminarios nos llevaría a considerarlo como un existencial. En este sentido, una consideración del cuerpo como un existencial podría estar en contra o hasta desvirtuar los planteamientos de Heidegger.
Además, si el cuerpo fuera un existencial no podría haber quedado excluido de la ontología fundamental de Ser y tiempo, como critica Sartre a Heidegger. Sin embargo, se podría contraargumentar señalando que el cuerpo se encontraría ya descrito en otros existenciales que darían cuenta de la corporalidad. Nos referimos con esto al ser-en-el-mundo (In-derWelt-sein) y a la disposición afectiva (Befindlichkeit), que como Haar (1986) afirma, podrían dar perfecta cuenta de fenómenos corporales. El cuerpo concebido como un existencial se encontraría disuelto en otros existenciales más fundamentales en la ontología fundamental de Ser y tiempo. Por esto, que la temática del cuerpo en Ser y tiempo no tenga primacía no implica necesariamente que el cuerpo no pueda ser considerado como un existencial. Solo se podría llegar a concluir lo anterior si se concibe Ser y tiempo como el "análisis definitivo" de la existencia humana. Pero Heidegger es enfático en señalar que los resultados obtenidos de la analítica existencial del Dasein en Ser y tiempo son aun provisorios más no definitivos. En este sentido, si los análisis de la existencia humana en Ser y tiempo son aun provisorios se podría replicar que Heidegger no alcanzó a desarrollar en su ontología fundamental el cuerpo como un existencial. Además, como sabemos, Ser y tiempo es un proyecto inconcluso, ya que se publicó su primera mitad la que solo incluía dos secciones de la primera parte quedando sin publicar la tercera sección de ella y la segunda parte (Acevedo, 2000). Si consideramos esto, se entiende que los planteamientos concernientes al cuerpo que Heidegger desarrollará luego en los Seminarios de Zollikon vienen a retomar lo que en Ser y tiempo había quedado solo bosquejado. Por esto, no parece errado afirmar que el cuerpo es desplegado como un existencial y que forma parte de un modo de ser del Dasein. 


\section{Referencias}

Acevedo, J. (2000). Tiempo y ser. Martin Heidegger. Madrid: Ed. Tecnos, 1999. Trad. de Manuel Garrido, José Luis Molinuevo y Félix Duque. Introducción de Manuel Garrido. Revista de Filosofía, 55, 195-198. Recuperado de https://semanariorepublicano.uchile.cl/index.php/RDF/article/download/44137/46149.

Aho, K. A. (2010). Heidegger's Neglect of the Body. Albany, New York: SUNY Press.

Benoist, J. (1994). Chair et corps dans les séminaires de Zollikon: La différence et le reste. En Autour de Husserl. L'ego et la raison, París: J. Vrin (pp. 107-122).

Buchanan, B. (2008). Onto-Ethologies: The Animal Environments of Uexküll, Heidegger, Merleau-Ponty, and Deleuze. Suny Press.

Butler, J. (2002). Cuerpos que importan. Sobre los límites materiales y discursivos del sexo. Buenos Aires, Argentina: Editorial Paidós.

Calvés, J. A. (2018). La biología en los conceptos fundamentales de la metafísica de Martin Heidegger: influencias de Hans Driesch y de Jakob von Uexküll. Filosofia e História da Biologia, 13(1), 61-70.

Ciocan, C. (2008). The question of the living body in Heidegger's analytic of Dasein. Research in Phenomenology, 38(1), 72-89. doi: 10.1163/156916408X262811

Derrida, J. (1989). La escritura y la diferencia (1967). Barcelona: Anthropos.

Derrida, J. (1992). Choréographies, in Points de Suspension. París: Éditions Galilée.

Escudero, J. A. (2011). Heidegger y el olvido del cuerpo. Lectora: revista de dones i textualitat, (17), 181-198. doi: 10.2436/20.8020.01.30

Franck, D. (1986). Heidegger et le problem de l'espace. Paris: Minuit.

Gallo, L. E. (2006). El ser-corporal-en-el-mundo como punto de partida en la fenomenología de la existencia corpórea. Pensamiento educativo, 38, 46-61. Recuperado de https://pensamientoeducativo.uc.cl/files/journals/2/articles/301/public/301-706-1-PB.pdf

Greisch, J. (1987). La parole heureuse: Martin Heidegger entre les choses et les mots (Vol. 47). Paris: Editions Beauchesne.

Haar, M. (1986). Le primat de la Stimmung sur la corporéité du Dasein. Heidegger Studies, 2, 67-80. doi: 10.5840/ heideggerstud198626

Heidegger, M. (2000a). Nietzsche I. Barcelona: Ediciones Destino.

Heidegger, M. (2000b). Carta sobre el humanismo. Madrid: Alianza Editorial.

Heidegger, M. (2001). Einleitung in die Philosophie (1928/29). Frankfurt del Meno: Vittorio Klostermann

Heidegger, M. (2007). Los conceptos fundamentales de la metafísica: mundo, finitud, soledad. Madrid: Alianza.

Heidegger, M. (2009). Principios metafísicos de la lógica. España: Síntesis.

Heidegger, M. (2013). Seminarios de Zollikon. DF, México: Herder.
Heidegger, M. (2017). Ser y tiempo. Santiago de Chile: Universitaria.

Heidegger, M., \& Fink, E. (2018). Heráclito: Seminario del semestre de invierno 1966-1967. Fondo de Cultura Económica.

Henry, M. (2007). Filosofía y fenomenología del cuerpo: ensayo sobre la ontología de Maine de Biran. Trad. Juan Gallo Reyzábal. Salamanca: Sígueme.

Hoffman, P. (2006). «The Body». En Dreyfus, H., Wrathall, M. (Eds.) A Companion to Phenomenology and Existentialism (pp. 253-262). Oxford: Blackwell Publishing

Johnson, F. (2014a). Corporalidad, sensibilidad y mundo: pensando la concreción del existir desde el pensamiento de Heidegger. Filosofia UNISINOS, 15(1), 52-66.

doi: 10.4013/fsu.2014.151.04

Johnson, F. (2014b). Cuerpo y método: el planteamiento heideggeriano del problema de la corporalidad en Zollikoner Seminare. Ideas y Valores: Revista Colombiana de Filosofía, 63(155), 7-30. doi: 10.15446/ideasyvalores.v63n155.32904

Kessel, T. (2014). Phänomenologie des Lebendigen: Heideggers Kritik an den Leitbegriffen der neuzeitlichen Biologie. Freiburg/ München: Verlag Herder GmbH

Lévinas, E. (2002). Totalidad e infinito: ensayo sobre la exterioridad. Salamanca: Ediciones Sígueme.

Le Breton, D. (2007). Adiós al cuerpo. Una teoría del cuerpo en el extremo contemporáneo. Colonia del Valle: La Cifra.

Merleau-Ponty, M. (1990). La structure du comportement. Paris: Quadrige/PUF.

Muñoz Pérez, E. (2015). Heidegger y la biología: Mecanismo y vitalismo en los conceptos fundamentales de la metafísica. Mundo, finitud y soledad (1929/30) de Martin Heidegger. Pensamiento. Revista de Investigación e Información Filosófica, 71(269), 1201-1216.

Nancy, J. L. (2003). Corpus. Madrid, España: Arenas Libros.

Neumann, H. (2015). El Dasein en Heidegger. Palabra y Razón, (7-8), 7-18.

Plessner, H. (1981). Die Stufen des Organischen und der Mensch: Einleitung in die philosophische Anthropologie. En Gesammelte Schriften, vol. 4. Frankfurt: Suhrkamp.

Rivera, J. E., y Stuven, M. T. (2008). Comentario a Ser y Tiempo de Martin Heidegger Volumen I: Introducción (Vol. 1). Santiago: Ediciones UC.

Rodríguez Suárez, L. P. (2012). Heidegger y el fenómeno del cuerpo. Apuntes para una antropología postmetafísica. Thémata. Revista de Filosofía, (46), 209-216. Recuperado de https:// revistascientificas.us.es/index.php/themata/article/view/395

Sartre, J. P. (1993). El ser y la nada. Barcelona, España: Altaya. Sanz Peñuelas, M. (2017). Fenomenología y enfermedad: aproximación al estudio de la experiencia patológica a luz del primer Heidegger (tesis doctoral). Universidad Autónoma de Barcelona, España. 


\begin{abstract}
Notas
1 Aquí hay que destacar los aportes fundamentales de Jean Luc Nancy (2003), Judith Butler (2002), David Le Breton (2007), entre otros.

2 Por ejemplo Greisch (1987), y Aho (2010) sostienen una ausencia total del cuerpo en la ontología fundamental de Heidegger. Mientras que Escudero (2011), Rodríguez Suárez (2012), y Johnson (2014b) afirman que a partir de los Seminarios de Zollikon se puede delimitar una interpretación heideggeriana de la corporalidad.

3 No es casualidad que Heidegger decida entablar estos diálogos con el psiquiatra suizo Medard Boss y realizar los seminarios en Zollikon. Hay que recordar que Medard Boss después de leer Ser y tiempo y no comprender nada en el período de guerras decide enviarle una carta en 1947 a Heidegger con la que comenzaría una larga amistad. En aquellos años de postguerra Heidegger tenía prohibido enseñar en la Universidad de Friburgo por sus vínculos con el nazismo. En estos seminarios Heidegger encontrará la posibilidad de retomar sus enseñanzas y dialogar con la medicina psiquiátrica, además de aceptar como discípulo a Medard Boss (antes discípulo de Freud). En una de sus cartas Heidegger así lo deja manifiesto: "El continuo encuentro del pensamiento filosófico y científico-natural que se da en la psiquiatría me parece naturalmente fructífero y estimulante" (Heidegger 2007, 347). $4 \quad$ Algo que no deja de extrañar si pensamos en el proyecto de destrucción de la metafísica que realizó Heidegger y que una de las formas para salirse de esta concepción metafísica del sujeto abstracto, vacío, e incorpóreo sería por medio del análisis del cuerpo.

5 Para ver más en profundidad el significado del término Dasein en la filosofía clásica alemana, y en específico, en la filosofía de Heidegger véase Neumann (2015).

6 Sartre usa la palabra "existencia" en el sentido de individuo. Mientras que Heidegger insiste en que el Dasein no puede interpretarse como un sujeto concreto que es être-la.

$7 \quad$ En el prefacio a Die Stufe des Organischen und der Mensch Plessner apunta a la necesidad de un sustento orgánico del existir descuidado en el pensamiento de Heidegger. En el prólogo escrito por Alphonse de Waelhens a la Structure du comportement de Merleau-Ponty se explica el anonimato del cuerpo en las estructuras existenciales desarrolladas por Heidegger. Para profundizar más en esta discusión consultar Hoffman (2006) quien describe claramente la posición desde la que tanto Sartre como MerleauPonty reprocharon a Heidegger la exclusión del cuerpo en Ser y tiempo.

8 Franck (1986), Greisch (1987), y Aho (2010) insistirán en la ausencia total del cuerpo en la ontología fundamental de Heidegger.

9 Para Heidegger, por ejemplo, el cuidado de sí (Selbstsorge), concebido como cuidado de cosas (Besorgen), es anterior a todo lo fáctico de la existencia, pues se trata con él de una estructura ontológica originaria.

10 La discusión de Heidegger con la biología y su tratamiento de la noción de organismo no será objeto de esta investigación. Para esto véase Muñoz Pérez (2015) y Calvés (2018).

11 Es importante mencionar que tras la publicación de los Schwarze Hefte de Heidegger se reactiva toda una discusión con la biología a partir de la reflexión de los conceptos de pueblo (Volk) o raza (Rasse). Lo interesante aquí es que Heidegger rechaza fuertemente el biologismo de la ideología nazi y su retórica racista, para pensar filosóficamente algunos de los principales problemas del nazismo. Muy en consonancia con la manera de pensar ontológicamente el cuerpo desmarcado de criterios biológicos. Sin embargo, esta relación no es objeto de esta investigación.

12 Heidegger utiliza el sentido del sustantivo Benommenheit que se deriva de sich benehmen, como atontamiento, entorpecimiento, o perturbamiento para designar el modo de ser del animal. Véase la nota al pie del traductor Alberto Ciria en Heidegger (2007).

13 Heidegger verbaliza el sustantivo der Leib para transformarlo en el verbo leiben. En este sentido, Heidegger acuña el neologismo leiben en los seminarios para evidenciar que el cuerpo (Leib) es fundamentalmente una actividad (leiben), es decir, un estar-siendo-cuerpo, un cuerpear. Pensemos, por ejemplo, que el ojo solo es ojo en tanto siendo la posibilidad de ver o sea el ojo está siendo su posibilidad de ser en tanto está viendo.

14 Para Michel Henry "Nuestro cuerpo es un poder, pero ese poder es un saber inmediato de sí, un saber que no presupone que esté abierto ya para nosotros el horizonte de la verdad del ser, sino que es en cambio el fundamento y el origen de esa verdad" (Henry, 2007, p. 139).
\end{abstract}

